\title{
QUAIS CARREIRAS E PARA QUAL SOCIEDADE? (I)
}

\section{$\star$ Jean-François Chanlat}

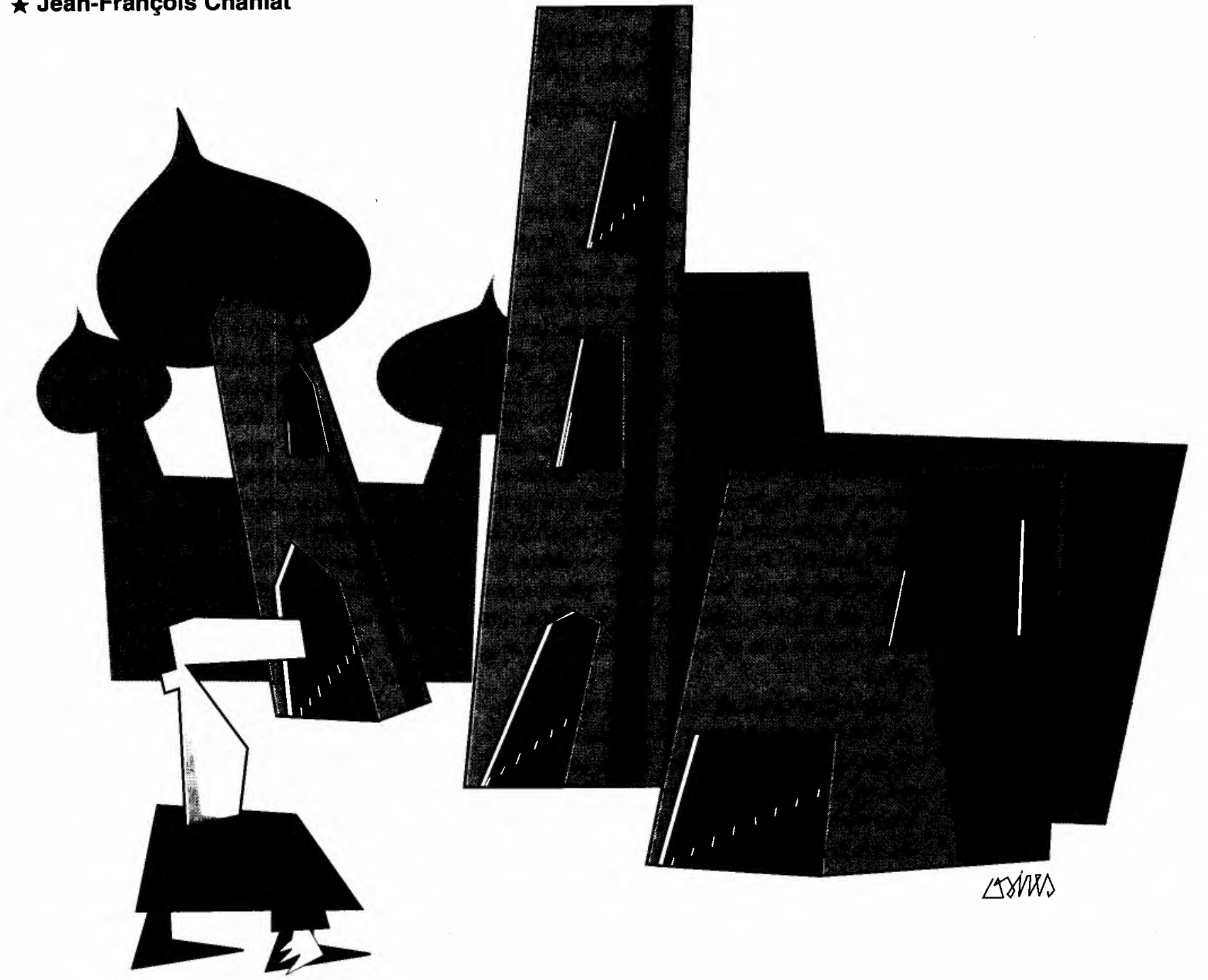

\section{PALAVRAS-CHAVE:}

carreira, gestão de carreira, modelos e tipos de carreira, carreiras e cultura.

\section{KEY WORDS:}

career,career management, models and kinds of careers, careers and culture.

$\star$ Professor da École des Hautes Éfudes Commerciales, Canadá.

(rae@eaesp.fgvsp.br) Assinatura E-mail 


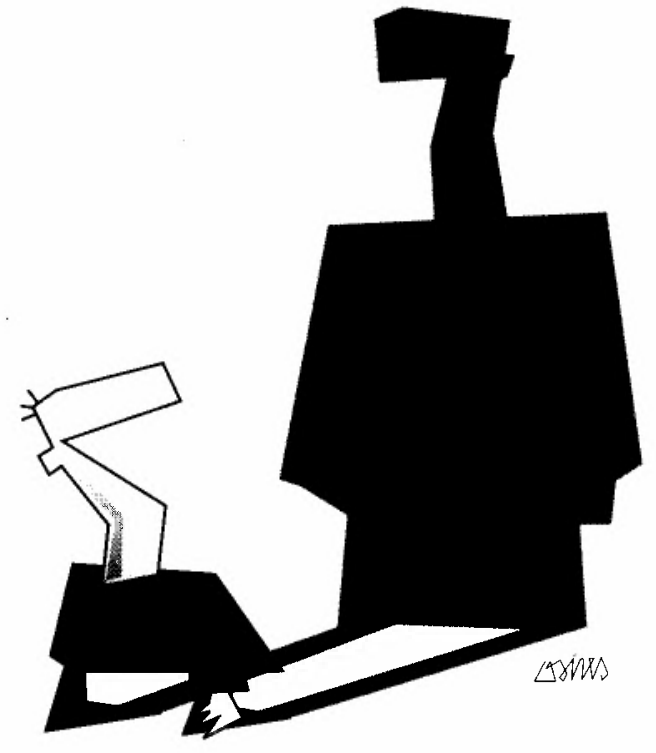

A

gestão de carreira é, hoje em dia, um tema da moda, em especial, nas empresas que se destacam com os últimos desenvolvimentos em matéria de gestão de recursos humanos. $\mathrm{O}$ meio universitário faz eco a essas múltiplas preocupações já há algum tempo, com publicações nesta área. Entretanto, esse interesse não é um fato recente. Há sempre entre as empresas - em particular entre as mais importantes - aquelas que estāo interessadas no desenvolvimento de seu pessoal. O que é novo, na verdade, é a importância que essa questão tomou nos

1. ARTHUR, M.B., HALL, D.T., LAURENCE, B.S. (Eds.) Handbook of career theory. New Yark: Cambridge University, 1989.

2. PETERS, $T$. WATERMAN, $R$ Le prix de l'excellence: les secrets des moilleurs entreprises. Paris: Inter éditions, 1983; OUCHI, W. Théorie Z: faire face au défi japonais. Paris: Inter éditions, 1982; ARCHIER, G., SÉRIEYX. L'entreprise du $3^{\text {em }}$ type. Paris: Editions du Seuil, 1984; AKTOUF, 0. Le management entre tradition et renouvellement. Montréal: Gaëtan Morin, 1989.

3. KANTER, R. M. Careers and the wealth of nations: a macroperspective on the structure and implications of career forms. Handbook of career theory. New York: Cambridge University, 1989.

4. GORZ, A. Métamorphoses du travail Quête du sens. Paris: Galilée, 1988. dias de hoje e o caráter sistemático das abordagens que se desenvolveram na matéria ${ }^{1}$.

Esta preocupação, como veremos adiante, configura-se em um contexto de profissionalização da gestão de Recursos Humanos e, mais genericamente, da renovação dos discursos gerenciais, que se apresenta desde o início dos anos $80^{2}$. A mobilização de pessoal torna-se central nestas novas tomadas de posição. Face à concorrência nacional e internacional e aos novos valores sociais, a empresa - se quer sobreviver - deve levar em consideração seu quadro de pessoal como um recurso fundamental. Para tanto, deve observar os desejos, as necessidades e as motivações de cada um. A gestão de carreira torna-se parte dessa estrutura política para assegurar que as pessoas recrutadas permaneçam na empresa. Se tais preocupaçōes são legíti- mas, persiste o fato de que a maior parte dos textos sobre carreira deixam de lado os aspectos mais macroscópicos e, em particular, as relaçóes que as carreiras mantêm com os aspectos econômicos, sociais, culturais e políticos mais amplos ${ }^{3}$. Todavia, é difícil falar a respeito de carreira sem evocar as estruturas socioeconômicas, as características do mercado de trabalho, os valores dominantes, a cultura na qual a empresa está mergulhada e o contexto histórico dentro do qual os encaminhamentos profissionais se inscrevem. Este é o assunto que o presente artigo pretende abordar. A pós observamos como a idéia de carreira é uma noção moderna e aquela de gestão de carreira é uma idéia ainda mais contemporânea, deter-nos-emos no enraizamento social das carreiras, através dos principais perfis e modelos que encontramos desde o fim da Segunda Guerra Mundial. Nós nos inclinaremos, então, sobre os paradoxos e os desafios que a gestão de carreira enfrenta atualmente, no momento da racionalização e precarização do trabalho ${ }^{4}$.

\section{CARREIRA E SOCIEDADE: UM BREVE RELATO HISTÓRICO}

A noção de carreira é uma idéia historicamente recente, aparecendo no decorrer do século XIX, assim como suas derivadas: carreirismo e carreirista, surgidas no século XX. A própria palavra "carreira", como 
nos indica o dicionário, em sua acepção moderna, quer dizer: "um oficio, uma profissāo que apresenta etapas, uma progressão". Dito de outro modo, a idéia de carreira, nasce com a sociedade industrial capitalista liberal.

Ao contrário da sociedade feudal, marcada por uma divisão social muito estanque entre o Clero, a Nobreza e o Terceiro Estado (camponeses, artesãos, mercadores etc.) e por uma grande desigualdade social $^{5}$, a sociedade industrial capitalista liberal está, com efeito, fundada sobre as idéias de igualdade, liberdade de êxito individual e progresso econômico e social ${ }^{6}$. Dentro deste quadro, fazer carreira torna se possível, em teoria, para todo mundo, porém, na prática, como sabemos, é muitas vezes diferente. A ideologia individual de êxito, a despeito de seus limites, está no centro da ordem social moderna. Esta ideologia é, em particular, marcante na América do Norte, onde a herança feudal foi inexistente, a terra facilmente disponível e as distâncias sociais mais reduzidas do que na Europa ${ }^{7}$. Tal fato permitiu a Mills escrever que "na América, o êxito foi um fato universal, uma imagem atraente, um motivo poderoso e um verdadeiro modo de vida"8. Comparativamente ao modelo único de êxito social fundado sobre o enobrecimento, ou seja, sobre a passagem de uma condição social a outra, encontrada no Antigo Regime, a sociedade capitalista industrial liberal emergente abre a porta a modelos de sucesso muito variados e encoraja a promoção social. É, neste momento, que a carreira, no sentido moderno, nasce. Anteriormente, cada um se dedicava ao exercício de funçōes que sua origem social e tradiçāo lhes tinham destinado. O reconhecimento e a mobilidade social nāo eram possíveis, a nāo ser pela boa vontade do monarca e sendo que esta deveria preservar o respeito às estruturas aristocráticas. O caso de Mozart é inteiramente exemplar. Como lembra N. Elias, o artista, mesmo célebre, é ainda no século XVIII, considerado pela maioria da nobreza como "um doméstico superior" . Mozart é o primeiro músico a se rebelar contra esta condiçāo. Ele pagará o preço pela rejeição social. No século XIX, isto não ocorrerá mais. $\mathrm{O}$ artista poderá fazer carreira sozinho. Ele não estará mais automaticamente submetido a um senhor.

\section{Toda saciedade, independente de}

seu tipo, fornece os quadros no

interior dos quais as carreiras

nascem, desenvolvem-se

e morrem.
A carreira não estará mais subordinada completamente à estrutura da classe aristocrática. Estamos a um passo de mudar a sociedade. Se a idéia de carreira é uma noção moderna no sentido que a entendemos hoje en dia, aquela de gestāo de carreira é ainda mais. É nos anos 80 que vai aparecer a idéia de que a empresa deve preocuparse em gerir as carreiras de seu pessoal. Esta preocupaçāo, relativamente nova dentro de sua formulação, decorre da importância que a empresa adquire no decorrer dos anos $80^{10}$ e da profissionalização da gestão que ocorre em todos os países industrializados, ambos durante o mesmo período" ${ }^{11}$. O termo gestāo torna-se uma palavra da moda. É dentro deste contexto de reabilitaçâo da empresa e de hegemonia do discurso gerencial que surge a noção de carreira. Ela é igualmente alimentada pelo novo discurso sobre a gestão dos recursos humanos. De agora em diante, "o capital humano" torna-se essencial nas práticas de gestão. A gestão de carreira é encarregada de fazer frutificar melhor os interesses das empresas e de seu pessoal. Se este discurso novo, năo é, hoje em dia, sem paradoxos, cabe ainda considerar que esta gestão não pode ser feita sem que se leve em conta o enraizamento social das carreiras.

\section{O ENRAIZAMENTO SOCIAL DAS CARREIRAS}

Toda sociedade, independente de seu tipo, fornece os quadros no interior dos quais as carreiras nascem, desenvolvemse e morrem. A sociedade industrial capitalista liberal, que se define pela mobilida-
5. BLOCK, M. La société fendale. Paris: Albin Michel, 1968; WINOCK, M. 1789 L'année sans pareille: chronique. Paris: O. Orban, 1988.

6. ARON, R. Dix-huit leçons sur la société industrielle. Paris: Gallimard, 1964.

7. TOCQUEVILLE, A. De la démocratie en Amérique. $\mathrm{Pa}$ ris: Gallimard, 1951.

8. MILLS, C. W. Les cols blancs. Paris: Éditions du Seuil, 1966.

9. ELIAS, N. Mozart sociologie d’un génie. Paris: Seuil, 1991.

10. ROUSSEAUX, N. (dir). Le culte de l'entreprise. Autrement, 100, Sept. 1988; SAINSAULIEU, R. (dir.) L'entreprise une affaire de société. Paris: Fondation nationale des sciences politiques, 1990.

11. MINTZBERG, H. Mintzberg on management: inside our strange world of organizations. New York: Free Press, 1989. 


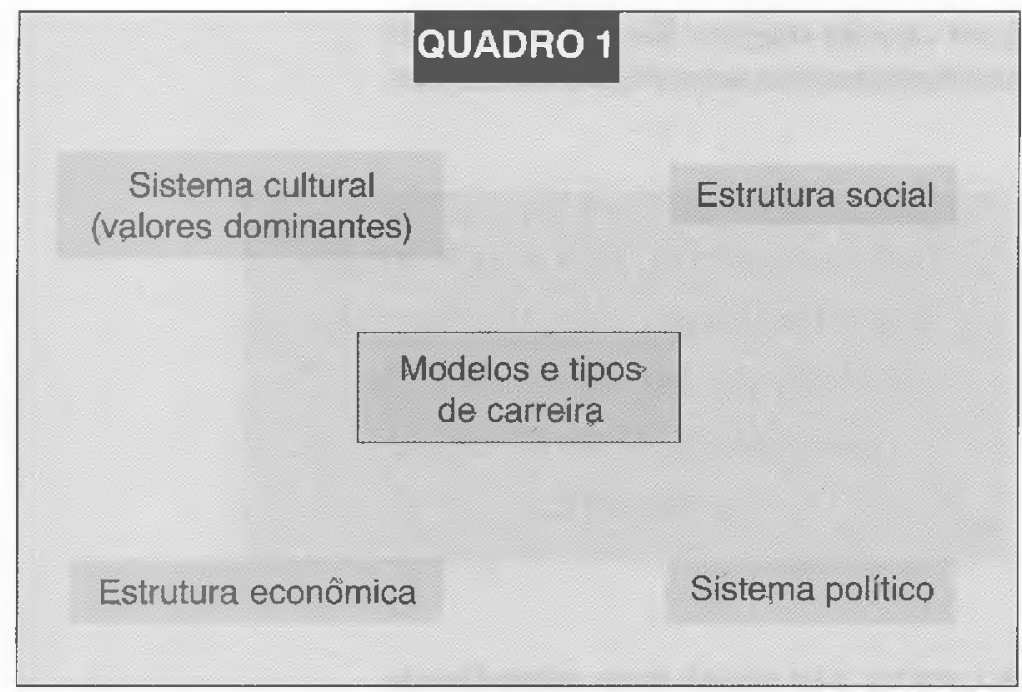

12. DUNPHY, D. An historical review of the literature on the Japanese enterprise and it's management. The enterprise and management in east Asia Hong Kong Centre of Asians Studies, University of Hong Kong, 1986, p. 334-68.

13. Le Japon rejette ses enfants qui ont vu du pays. Courrier internacional, n. 70, p. 15, jeudi 5 mars 1992.

14. HOFSTEDE, G. Culture's consequences, international differences in work-related values. Beverly Hilis: Sage, 1980.

15. DUNPHY, D. An historical review of the literature... Op. cit.

16. MAURICE, M., SELLIER, F., SYLVESTRE, J. P. Politiques industrielles en france et en Allemagne. Paris: PUF, 1982.

17. JOFFRIN, L. Les diplômes ne suffisent plus. Le nouvel observateur, n. 1437, 21-27 mai 1992. de, não escapa desta regra. Por que ela é constitutiva desta sociedade. Desde o início da revolução industrial, numerosas profissōes apareceram e desapareceram. Essas mudanças na estrutura dos empregos fazem parte da própria natureza de nossas sociedades. Todavia, a cultura e a estrutura social de cada sociedade acabam por modificar as configuraçōes que os tipos e os modelos de carreira podem ter de um país a outro.

Apresentamos numerosas situaçóes por testemunho.

\section{Exemplo 1}

Se tomarmos o caso da grande empresa japonesa, podemos fazer certas constatações:

- só um pequeno número de mulheres podem fazer carreira;

- as grandes organizaçōes fazem distinção entre antiguidade e posiçāo hierárquica, permitindo aos indivíduos progredirem em reconhecimento e em salário, mesmo quando as possibilidades de mobilidade vertical são pequenas e as promoções raras;

- todos os executivos são forçados a fazer um rodízio de atividades na empresa, acumulando uma série de experiências que vão da oficina a um grande número de serviços;

- o emprego está garantido até os 55 anos $^{12}$, - os japoneses que tiveram uma experiên- cia no exterior não são bem reconhecidos no seu retorno ao Japāo ${ }^{13}$.

Esta série de constatações decorrem diretamente do fato de que a cultura é orientada por valores masculinos ${ }^{14}$, a promoção passa por um conhecimento global da empresa e uma direção voltada para o coletivo, sendo que o engajamento deve ser total, uma vez que o indivíduo não é nada sem o grupo, já que a cultura japonesa rejeita aqueles que não se adaptam ao modelo padrāo ${ }^{15}$.

\section{Exemplo 2}

Se tomarmos agora o caso da Alemanha, observaremos que nas empresas alemãs:

- a diferença salarial entre os operários e os executivos é uma das menores dos países industrializados;

- os operários beneficiam-se de uma formação profissional de qualidade;

- os níveis hierárquicos são menores do que numa empresa francesa ${ }^{16}$, como veremos posteriormente;

- os executivos são recrutados em funçăo de sua experiência profissional e estes sobem escalões, um a um.

\section{Exemplo 3}

O exemplo alemão contrasta estranhamente com o caso da empresa francesa, na qual verificamos que:

- as diferenças entre os operários e os executivos são maiores;

- os postos de direção são reservados aos diplomas das grandes escolas;

- o reconhecimento e a especializaçăo sāo, antes de tudo, uma questão de prestígio do diploma obtido;

- a experiência estrangeira é relativamente pouco valorizada ${ }^{17}$.

Esta comparação França-Alemanha, revela-nos quando dois países europeus vizinhos podem ter diferenças em suas gestôes de carreira. Tais diferenças näo sāo compreensíveis se não as remetermos à cultura, ao sistema de educação e ao modo de reprodução das elites. Como mostrou recentemente d'Iribarne, o gerenciamento 
à francesa distingue-se da gestāo à americana ou à holandesa ${ }^{18}$. As relações sociais, as relações de autoridade e a carreira são vividas diferentemente de um país a outro. A França moderna - herdeira da ordem social feudal e de valores aristocráti$\cos$ - realiza uma gestão baseada na distinção social e na honra, enquanto que os Países Baixos - nascidos de um reagrupamento igualitário de províncias e de cidades desiguais - desenvolveram uma gestão mais igualitária, mais consensual. Os Estados Unidos - fundados por mercadores religiosos - desenvolveram uma lógica contratual baseada na eqüidade e em uma certa ética puritana. É no cerne destes enquadramentos sociais que os modelos de carreira vão se distinguir de uma empresa a outra. Deste modo, a carreira na França está funidada sobre a nobreza do diploma ${ }^{19}$, a carreira alemã, sobre a experiência profissional, a carreira americana sobre os méritos e performances individuais e a carreira holandesa sobre a especialização e o espírito igualitário ${ }^{20}$.

\section{Exemplo 4}

Se colocarmos o caso da Suécia, vamos estar diante de um outro tipo de experiência. Como todos sabemos, a Suécia é um dos países mais igualitários do mundo:

- a igualdade entre os sexos é, ali, a mais forte;

- as diferenças de renda são as mais reduzidas;

- as diferenças de comportamento entre as classes são menores do que nos outros países industrializados.

Estas característiscas são reforçadas por um sistema de proteçāo social bem elaborado e por uma forte fiscalização. É neste contexto que as carreiras dos executivos suecos se desenvolvem. Segundo certos analistas do cenário sueco, parece que os executivos não são muito inclinados à mobilidade geográfica e nem entusiastas com as promoções que impliquem mudanças. Podemos compreender essa situação através do fato de que o acréscimo de salário e vantagens sociais e materiais, associados a este gênero de promoçāo, são relati-

\begin{tabular}{|c|c|}
\hline TABELA 1 Os modelos de carreira \\
\hline O modelo tradicional & O modelo moderno \\
\hline um homem & um homem e/ou uma mulher \\
$\begin{array}{c}\text { - pertencente aos grupos } \\
\text { socialmente dominantes } \\
\text { estabilidade } \\
\text { - progressão linear vertical } \\
\text { sociais variados } \\
\text { instabilidade } \\
\text { progressão descontínua } \\
\text { vertical e horizontal }\end{array}$ \\
\hline
\end{tabular}

vamente falíveis em relação àqueles que se observam, em situaçōes comparáveis, em outros lugares no Ocidente. Isto se explica também pelo fato de que o próprio conjunto de executivos tem uma carreira e a cultura igualitária da Suécia não favorece a idéia de promoção, já que os suecos permanecem ligados a um equilíbrio entre a vida profisional e a vida familiar, preservando seus momentos de lazer e seu gosto pela natureza ${ }^{21}$, não vendo no individualismo um valor em $\mathrm{si}^{22}$.

Todos estes exemplos, extraídos de países diferentes, ilustram o quanto a gestão de carreira não tem o mesmo valor e o quanto esta idéia está enraizada socialmente na cultura, na história e nas estruturas sociais próprias de cada país. Porém, além das diferenças observadas entre as empresas de países distintos, podemos depreender certos modelos e perfis comuns.

\section{Modelos e tipos de carreira}

Nas sociedades industrializadas, as carreiras podem ser reagrupadas em dois grandes modelos e quatro tipos principais. O modelo engloba as características fundamentais da carreira em nossa sociedade, enquanto os tipos remetem ao aspecto profissional desta carreira, ou seja, aos diferentes encaminhamentos possiveis oferecidos a uma pessoa no ambiente de trabalho.

\section{Dois modelos de carreira}

Quando lançamos um olhar sobre a carreira nas nossas sociedades desde a virada
18. D'IRIBARNE, P. La logique de I'honneur. Paris: Éditions du Seuil, 1989.

19. BOURDIEU, P. La noblesse d'État. Paris: Éditions de minuit, 1989.

20. DIRIBARNE, P. La logique... Op. cit.

21. LAWRENCE, P., SPYBEY, T. Management and society in Sweden. Londres: Routledge \& Kegan Paul, 1986.

22. GUILLET de MONTHOUX, P. Le modèle suédois, dans $D$. Schnapper et $\mathrm{H}$. Mendras, Six manières d'étre européen. $\mathrm{Pa}$ ris: Gallimard, 1990. 


\begin{tabular}{|c|c|c|c|c|c|}
\hline $\begin{array}{l}\text { Tpos de } \\
\text { carreira }\end{array}$ & $\begin{array}{l}\text { Recursos } \\
\text { princlpals }\end{array}$ & $\begin{array}{l}\text { Elemento central de } \\
\text { ascensto }\end{array}$ & Tpos de organização & Limites & $\begin{array}{l}\text { Tipos de } \\
\text { sociedades }\end{array}$ \\
\hline Burocrática & Posiçāo hierárquica & $\begin{array}{l}\text { Avanço de uma posiçăo } \\
\text { hierárquica à outra }\end{array}$ & $\begin{array}{l}\text { Organizaçóes de grande } \\
\text { porte }\end{array}$ & $\begin{array}{l}\text { O número de } \\
\text { escalóes existentes }\end{array}$ & $\begin{array}{l}\text { Sociedade de } \\
\text { empregados }\end{array}$ \\
\hline Profissional & Saber e reputaçăo & $\begin{array}{l}\text { Profissāo, perícia } \\
\text { Habilidades profissionais }\end{array}$ & $\begin{array}{l}\text { Organização de peritos } \\
\text { Burocracia } \\
\text { Proflissional }\end{array}$ & $\begin{array}{l}\text { O nível de perícla e } \\
\text { de reparaçáo }\end{array}$ & $\begin{array}{l}\text { Sociedade de } \\
\text { peritos }\end{array}$ \\
\hline Empreendedora & $\begin{array}{l}\text { Capacidade de } \\
\text { criaçáo } \\
\text { inovaçáo }\end{array}$ & $\begin{array}{l}\text { Criaçáo de novos valores, } \\
\text { de novos produtos e } \\
\text { serviços }\end{array}$ & $\begin{array}{l}\text { Pequenas e médias } \\
\text { empresas } \\
\text { Empresas artesanais, } \\
\text { culturais, comunitárias } \theta \\
\text { de caridade }\end{array}$ & $\begin{array}{l}\text { A capacidade } \\
\text { pessoal } \\
\text { As exigências } \\
\text { externas }\end{array}$ & $\begin{array}{l}\text { Sociedade que } \\
\text { valoriza a iniciativa } \\
\text { individual }\end{array}$ \\
\hline Sociopolftica & $\begin{array}{l}\text { Habilidades sociais } \\
\text { Capital de relaçōes }\end{array}$ & $\begin{array}{l}\text { Conhecimento } \\
\text { Relaçóes } \\
\text { Parentesco } \\
\text { (Rede social) }\end{array}$ & $\begin{array}{l}\text { Familiar } \\
\text { Comunitária } \\
\text { de Clãs }\end{array}$ & $\begin{array}{l}\text { O número de } \\
\text { relaçōes conhecidas } \\
e \text { ativas }\end{array}$ & Sociedade de clâs \\
\hline
\end{tabular}

23. DAVID, H. Femmes et emplois. Le défi de l'égalité. Québec: Presses de l'Uniserité du Québec, 1986.

24. MILLS, C. W. Les cols blancs... Op. cit.

25. HAREL-GIASSON, F. MARCHIS-MOUREN, M. F. Débuts de carrièrre au féminin. Gestion, v. 17, n. 1, p. 50-9, 1992.

26. LANGLOIS, S. et coll. La société québécoise en tendances 1960-1990. Montréal: Institut québécois de recherches sur la culture, 1990.

27. HAREL-GIASSON, F. ROBICHAUD, J. (dir.) Tout savoir sur les cadres féminins d'jei. Montréal: Les Presses HEC, 1988; Corporate women how much progress? Business Week, 8 juin. 1992.

28. LANGLOIS, S. et coll. La société québécoise en... 0p. cit.

29. MCNEIL, J. La diversification des ressources humaines québécoises. Gestion, v. 17, n. 2, p. 39-48, mai 1992. do século, nós podemos facilmente observar dois grandes modelos: o modelo tradicional e o moderno. O primeiro corresponde àquele que tem sido o dominante, hoje em dia; o segundo descreve aquele que emerge a partir dos meados dos anos 70 .

Como nos mostra a tabela 1 , tradicionalmente a carreira é feita por um homem, pertencente aos grupos socialmente dominantes. Ela é marcada por uma certa estabilidade e uma progressão linear vertical. Esse modelo tradicional está em perfeita ressonância com uma sociedade em que a divisão sexual do trabalho interditou por todas as práticas a carreira das mulheres ${ }^{23}$, a homogeneidade da população era maior, a instrução estava desigualmente repartida e as grandes organizações ofereciam empregos, estabilidade e aberturas ${ }^{24}$. Hoje em dia, esse modelo tradicional está ainda largamente presente mais em certos países do que em outros, sendo o Japão - entre os países industrializados - exemplar, sob este ponto de vista; e, mais em certas indústrias do que em outras, como no caso de engenharia e finanças, mesmo em sociedades mais avançadas no domínio da igualdade sexual ${ }^{25}$. Contudo, a partir dos anos 70, surge um outro modelo, menos tradicional, resultante das mudanças sociais que vamos conhecer nas sociedades, no decorrer dos últimos trinta anos:
- feminização do mercado de trabalho;

- elevação dos graus de instrução;

- cosmopolitação do tecido social;

- afirmação dos direitos dos indivíduos;

- globalização da economia;

- flexibilização do trabalho etc ${ }^{26}$.

Esse novo modelo caracteriza-se pela variedade ao mesmo tempo sexual e social. Numerosas mulheres iniciam, com efeito, em nossos dias, carreiras com os mesmos títulos que os homens ${ }^{27}$. Se a democratização da educação ajuda as mulheres neste processo, permite igualmente a muitos indivíduos de origem modesta o acesso a este modelo ${ }^{28}$. Mais recentemente, a diversidade étnica cada vez maior de nossa população só reforça este fenômeno de diversificação de carreiras ${ }^{29}$. Ao contrário do modelo tradicional, esse modelo é marcado pela instabilidade, descontinuidade e horizontalidade. No presente momento, as carreiras são, com efeito, menos estáveis e menos lineares do que antes. A chegada maciça das mulheres, as mudanças tecnológicas e a reestruturação da economia vão introduzir uma variedade de comportamentos anteriormente desconhecidos. Podemos parar de trabalhar para estudar, estudar trabalhando, educar as crianças e voltar ao mercado de trabalho e aos estudos, reorientar a carreira mais freqüente- 
mente, tirar uma licença sabática etc. Todas essas coisas, que eram menos realizáveis no passado, introduzem rupturas no modelo de carreira tradicional ${ }^{30}$. Veremos, um pouco mais adiante, que esta instabilidade e esta descontinuidade não sāo, ainda hoje, sinônimos de progresso e de bemestar para todos aqueles a elas submetidos. As aberturas e os encaminhamentos profissionais no interior desses modelos são, por outro lado, múltiplos. Como mostra a tabela 2 , nós os reagrupamos em quatro grandes tipos:

- burocrático;

- profissional;

- empreendedor;

- sociopolítico.

Cada um desses tipos nāo só recupera uma tarefa precisa, mas indica também uma lógica no caminho a seguir, a natureza das aberturas profissionais e o sistema de recompensas a ele associado.

\section{A carreira de tipo burocrático}

A carreira de tipo burocrático, como seu nome indica, remete às estruturas burocráticas da organização. Caracteriza-se por:

- divisão elaborada do trabalho;

- rígida hierarquia de papéis e de estatutos;

- regulamentação onipresente;

- centralização de poder;

- impessoalização das relaçōes.

A organização burocrática oferece um avanço dentro de uma carreira que está estritamente dentro da pirâmide organizacional ${ }^{31}$. A cada nível concede-se uma certa responsabilidade, um certo salário e vantagens sociais formalmente definidas. A antigüidade e os concursos são geralmente a base da seleçāo, do recrutamento e da promoção. O recurso central é a posição que se ocupa, e os números de escalões existentes estabelecem os limites deste tipo de carreira. São numerosos os indivíduos que trabalham dentro de tal universo. As grandes organizaçōes de natureza privada, pública, paraestatal, ou cooperativa, têm, efetivamente, diversos graus burocráticos ${ }^{32}$.
Este tipo de carreira predominou durante muitos decênios, com o crescimento das grandes empresas e com a criação daquilo que Mills chamou de La societé d'employes $^{33}$, no decorrer da primeira metade do século $X X$, ou com o que alguns qualificaram de "sociedades burocráticas", epíteto que designou as experiências sociais conduzidas até recentemente pelos países do Leste e pela URSS ${ }^{34}$. Hoje, esse tipo de carreira está seriamente ameaçado pela crise do Estado, pela reestruturação das empresas, pelo achatamento das hierarquias, pelo apelo à criatividade, inova-

\section{Ao criar abertura para as mulheres}

e para as minorias, este novo tipo dessociedade está em vias de instalar uma nova divisặo do trabalho, o qual questionará a própria noção de carreira para a maioria da população.

çāo e iniciativa individual que surgem no novo discurso gerencial ${ }^{35}$. Historicamente associada à grande empresa oligopolista ou monopolista e ao seu desenvolvimento, esse tipo de carreira parece, segundo certas análises, pouco adaptado à nova ordem, à concorrência internacional, às mudanças tecnológicas e ao apelo à flexibilidade, que minam pouco a pouco as estruturas burocráticas $^{36}$.

\section{A carreira de tipo profissional}

A carreira de tipo profissional baseia-se no monopólio de um certo saber, da especializaçăo, da profissão e da reputação $0^{37}$. Ela não é uma carreira de tipo vertical, como é, forçosamente, a carreira burocrática. Seu avanço se faz, sobretudo, no interior da disciplina profissional, à medida que o conhecimento e a experiência se acumulam. Um advogado, um engenheiro, um médico, um notável, um professor ou um pesquisador podem muito bem, ascender a postos de direção, porém, na maioria dos casos, o avanço em sua carreira estará, so-
30. LANGLOIS, S, et coll. La société québécoise en... Op. cit; HAREL-GIASSON, F., MARCHIS-MOUREN, M. F. Op. cit.

31. WEBER, M. Économie et société. Paris: Plon, 1972.

32. GROZIER, M. Le phénomène bureaucratique. Paris: Éditions du Seuil, 1962: CLEGG, Modern organization. Londres: Sage, 1990 .

33. MILLS, C. W. Les cols blancs... Op. cit.

34. CASTORIADIS, C. La SOciété bureaucratique. Paris: UGE, 1973.

35. MESSINE, P. Les saturniens. Paris: La découverte, 1987.

36. KANTER, R. M. Careers and the wealth of... Op. cit.

37. SÉGUIN, F., HAMEL, P. LeS hauts et les bas de la profession comptable. Gestion, v. 7, п. 1, p. $18-24,1982$. 
bretudo, ligado à sua reputação e ao seu saber. Enquanto a pessoa tem os meios e a capacidade de aprender e de aperfeiçoarse, ela pode crescer no interior de sua profissão. Ao contrário da carreira burocrática associada, muitas vezes, a uma organização em particular, a carreira de tipo profissional oferece uma mobilidade maior, uma vez que seu recurso central é a especialização reconhecida. Os profissionais tendem a desenvolver uma lealdade maior em relação à profissão do que em relação à organização que o emprega. Isto explica porque eles têm, em geral, maior mobili-

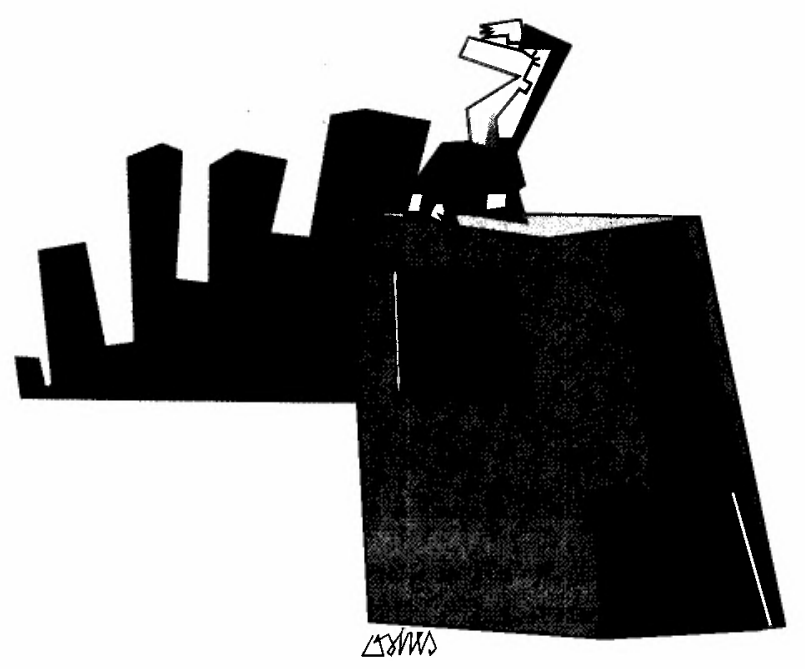

38. MILLS, C. W. Les cols blancs...Op. cit., SÉGUIN, F., HAMEL, P. Les hauts et les bas de la profession... Op. cit.

39. MINTZBERG, H. Mintzberg on management... Op. cit.

40. ALLEN, T. J., KATZ, R. Managing engineers and scientists: some new perspectives. In: EVANS, P., DOZ, Y., LAURENT, A. Human resource management in international firus. Londres: MacMillan, 1989, p. 191-99.

41. MINTZBERG, H. Mintzberg on management... Op. cit.

42. TOULOUSE, J. M. L'entrepreneurship. Montréal: Les Presses HEC, 1979.

43. MILLS, C. W. Les cols blancs... Op. cit.
Contudo, um excesso de profissionalização, notamente em gestão, comporta um certo risco, simultaneamente, para as sociedades, para as organizações e para os indivíduos, porque pode desembocar num modo de gestão abstrato, formado por um grupo de especialistas geralmente distantes da realidade bem concreta da vida organizacional ${ }^{41}$.

\section{A carreira de tipo empreendedor}

A carreira de tipo empreendedor está ligada às atividades de uma empresa independente, traçadas por uma pessoa. Esse tipo de carreira é, em geral, identificada com o empreendedor econômico. Hoje em dia, há uma concepção mais ampla deste tipo de carreira. Os artistas, os fundadores de empresas culturais, comunitárias ou beneficentes são aqui considerados sob o mesmo título que os artesãos, os comerciantes e os patrões das pequenas e médias empresas ${ }^{42}$.

A carreira empreendedora é constitutiva de nossa sociedade capitalista liberal e de sua ideologia de sucesso individual. No decorrer do século XIX, ela foi particularmente valorizada, pois, era a ilustração da superioridade liberal sobre a sociedade aristocrática feudal. O sucesso não era mais fruto do nascimento mas sim resultado do talento, do trabalho e da poupança de um indivíduo honesto ${ }^{43}$. Já no século $X X$, a carreira do tipo empreendedor, sem desaparecer, foi largamente substituída pelos dois tipos de carreira precedentes. A complexidade dos problemas, a concentração das empresas, a expansão do Estado relegaram esta carreira ao segundo plano. Há alguns anos, a carreira de empreendedor, após ter sido eclipsada pela expansão das grandes organizaçóes, parece ressurgir de maneira interessante. Fatores como: as dificuldades do setor público, a crise do Estado-Previdência, as dispensas maciças em certas indústrias, a concorrência internacional parecem ter empurrado, por sua vez, os governos, as empresas e as sociedades para valorizarem novamente este tipo de carreira. Nos países do Leste, da era pós-comunista, e na ex-União Soviética, ela transformou-se num objeto de culto. Às vezes, para não dizer com freqüência, ela se confunde 
mesmo com aquilo que, certamente entre nós, consideraríamos como simples pirataria comercial. Mais arriscada do que os dois outros tipos de carreira, a carreira de empreendedor oferece, em caso de sucesso, recompensas materiais mais elevadas e, em certos casos, bem consideráveis. Basta pensar em todos estes empreendedores que partiram do nada e ficaram bilionários. Tal êxito não será jamais alcançado por um burocrata ou por um profissional de alto nível, a menos que, bem entendido, ele próprio se transforme em um empreendedor. Isto não impede que numerosas pessoas defendam, cada vez mais, o desenvolvimento do espírito de empreendimento e as características associadas ao empreendedor: criatividade, inovação, gosto pelo rísco, além de independência nos cargos executivos e nāo-executivos das grandes empresas para melhorar o desempenho: nasce, então, o intrapreneurship ${ }^{44}$. Nossa sociedade parece fazer desta, a grande carreira, por excelência. A precarizaçāo cada vez maior do trabalho e uma taxa de desemprego tenaz, podem levar às pessoas a criarem seu próprio emprego ${ }^{45}$. A pesar disto, pode-se questionar a qualidade deste novo tipo de carreira, o de tipo empreendedor.

\section{A carreira de tipo sociopolítico}

A carreira de tipo sociopolítico baseiase nas habilidades sociais e no poder de relações de que dispõe uma pessoa. O elemento central aqui náo é nem a posiçāo nem a especializaçāo ou a inovaçāo criadora, mas sim o capital de conhecimentos, de relaçôes e de pertencimento a um nível social e bem estruturado e entendido. É graças a esse nível de relaçōes que a carreira se constrói e as promoções são obtidas. Encontra-se, neste tipo de carreira, as empresas de tipo familiar, comunitária ou em clãs. É um tipo particularmente dominante em certas partes do mundo, notadamente na África negra, onde a solidariedade étnica tem maior importância, na maior parte do tempo, do que a competência profissional, as regras burocráticas ou o dinamismo empresarial ${ }^{46}$. Pode também ser observada dentro de nossas sociedades. Se este tipo de carreira parece legítimo, em
No presente momento, as carreiras

são, com efeito, menos estáveis e menos lineares do que antes. certos casos, como nas empresas familiares, por exemplo, ele é denunciado, muitas vezes, em outros universos, em especial dentro das estruturas burocratizadas, estando associado ao nepotismo. Não foi colocada a própria burocracia para justamente por fim à arbitrariedade e ao favoritismo ${ }^{47}$ ?

De certa forma, o capital de relaçōes desempenha um papel sobre os três tipos de carreira já apontados. A carreira não é, jamais, unicamente o fruto da sorte, da criatividade dos talentos ou da competência, ela é também o produto de um tecido de relações, como nos indicam certos estudos clássicos sobre a maneira em que as pessoas se reconduzem ao emprego. O particular no tipo de carreira sociopolítico, é que neste o capital de relaçóes domina largamente todo o resto. Em certas empresas, nas quais o caráter do clã é fortemente acentuado, ele substitui com vantagem, o diploma, os concursos, a antigüidade e a competência profissional.

O modelo tradicional e os tipos de carreira que descrevemos estão inscritos em uma sociedade baseada, até meados dos anos 70 , sobre a estabilidade, o enriquecimento, o progresso e uma divisāo sexual e social do trabalho bem delimitada. O modelo moderno emergente, ao qual aludimos, enraiza-se em um outro tipo de sociedade. Ao criar abertura para as mulheres e para as minorias, este novo tipo de sociedade está em vias de instalar una nova divisāo do trabalho, o qual questionará a própria noção de carreira para a maioria da população. Este importante paradoxo, que se liga às outras constataçōes, inquieta àqueles e àquelas que se preocupam justamente em gerir os encaminhamentos profissionais.
44. BRENNER, G., BRENNER, R. Intrapreneurships - le nouveau nom d'un vieux phénomène. Gestion, v. 13, n. 3, p.19-23, Sept. 1988

45. How to succeed without a joub. INC., juin. 1992.

46. KAMDEM, E. Temps et travail en Afrique. In: CHANLAT, J. F. (dir.) L'individu dans l'organisation: les dimensions aubliêes. Québec: Les Presses de I'Université Laval/ESKA 1990.

47. WEBER, M. Économie et société... Op. cit.

Artigo originalmente publicado na revista Gestion, v. 17, n. 3 , p. 100-11, 1992, sob o título Peut-on encore "faire-carrière? Tradução de Maria José Tonelli, revista por Edith Seligmann Silva, professoras do departamento de Fundamentos Sociais e Jurídicos da Administração da EAESP/FGV. 